TITLE:

\title{
Eurycyde flagella, a New Pycnogonid Species from Phuket Island, Thailand
}

$\operatorname{AUTHOR}(S)$ :

Nakamura, Koichiro; Chullasorn, Supawadee

\section{CITATION:}

Nakamura, Koichiro ...[et al]. Eurycyde flagella, a New Pycnogonid Species from Phuket Island, Thailand. PUBLICATIONS OF THE SETO MARINE BIOLOGICAL LABORATORY 2000, 39(1): 1-7

ISSUE DATE:

2000-12-25

URL:

http://hdl.handle.net/2433/176295

RIGHT: 
Publ. Seto Mar. Biol. Lab., 39 (1): 1- 7, 2000

\title{
Eurycyde flagella, a New Pycnogonid Species from Phuket Island, Thailand ${ }^{*}$
}

\author{
KOICHIro NaKamUra ${ }^{1)}$ and SUPaWAdeE CHULlasorN ${ }^{2)}$ \\ 1) Japan Women's College of Physical Education, Setagaya, Tokyo, \\ 157-8565 Japan \\ 2) Ramkhamhaeng University, Bangkok, 10240 Thailand
}

\begin{abstract}
A new species of pycnogonid, Eurycyde flagella, from an intertidal coral reef at Phuket, Thailand, is described and figured, and compared with similar species. This is the first record of the genus from the Andaman Sea. The new species is distinct from other species most characteristic with the two long spines but no tubercle on coxa 1. It differs in the combination of number of long spines on the ocular tubercle, single tall dorsodistal tubercles on anterior three pairs of lateral processes, and shape and location of femoral cement gland of male. A key to all known species of the genus Eurycyde is presented.
\end{abstract}

Key words: Pycnogonida, Eurycyde flagella, Thailand, Andaman Sea

\section{Introduction}

There are only a few records of pycnogonids collected from waters adjacent to Thailand. The genus Eurycyde has not been recorded from Thailand and the Indian Ocean, including the Andaman Sea. A specimen was collected in this genus from the South China Sea, the nearest area to the Indian Ocean. In the present paper, a new species of the genus Eurycyde, is described from the coral reef of Phuket Island, the Andaman Sea, near the Phuket Marine Biological Center.

The genus Eurycyde was elaborated by Stock (1955) with a key for five known species, and further by Child (1988) with a key for ten species. Since then, no further key for this genus has been given. In this paper, the authors present a key for 19 species of the genus Eurycyde, adding nine more species to those reported by Child.

The holotype and paratype are deposited in the Reference Laboratory, Phuket Marine Biological Center (PMBC).

\section{Family Ammotheidae \\ Genus Eurycyde Schioedte, 1857}

Species in the genus Eurycyde are all closely related in their morphology. All the species in this genus have two-segmented proboscis, which is very unique to the genus and most valuable for identification. Most species of Eurycyde look alike in cherifores and palpi, and haveing long feathered spines on the legs.

Genus Eurycyde is also known for dimorphism as pointed by Child (1988). He listed $E$. acanthopus Stock (holotype female) and E. curvata Child (holotype male) under the same key, but they can be distinguished by the number of distal tubercles on the lateral processes which is indicated in the present key.

\footnotetext{
"Contributions from Phuket Marine Biological Center, No.34
} 
1. Ocular tubercle with long distal spines ...................................... 2

Ocular tubercle glabrous or with one or more short spines ..................... 9

2. Lateral processes with dorsodistal tubercles .....................................

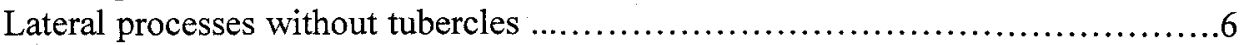

3. First coxae without tubercles, with two long spines, spines with many short setae; ocular tubercle with 3 long spines $\ldots \ldots \ldots \ldots \ldots \ldots \ldots \ldots \ldots \ldots \ldots . \ldots \ldots . \ldots \ldots$ flagella $\mathrm{n} . \mathrm{sp}$.

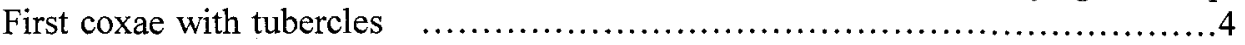

4. Dorsodistal tubercles on lateral processes tall, ocular tubercle with 6 spines; coxa 1 with 2 heavy conical tubercles .............................E. raphiaster Loman Dorsodistal tubercles on lateral processes low ....................................5

5. First coxae posterior tubercles with long spines, spines with many setae; Ocular tubercle with 5 long spines....................................... sertula Child First coxae posterior tubercles without long spines; Ocular tubercle with 7 long

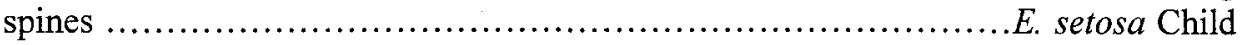

6. Species robust, anterior lateral processes touching; coxa 1 with small posterior tubercles or none; chelifore robust, 1st segment little longer than 2nd ( $q$ only) E. gorda Child Species more slender, lateral processes not touching $\ldots \ldots \ldots \ldots \ldots \ldots \ldots \ldots \ldots \ldots . \ldots \ldots$

7. First coxae anterior tubercles almost as long as posterior tubercles; Ocular tubercle with 2 or more long spines ................................................8 First coxae anterior tubercles 0.5 to 0.6 as long as posterior tubercles; Ocular tubercle with more than 5 long spines ....................... E. longioculata Müller

8. Lateral processes separated distally by half their diameters; ocular tubercle with 1 long anterior spine and 1 short posterior spine; abdomen with 2 long spines; coxa 2 with long spines at middle ................................... diacanta Stock Lateral processes touching or separated by narrow intervals less than half their diameters; ocular tubercle with 2 long spines; abdomen with 5-6 long spines; coxa 4 without long spines ...................................... longisetosa Hilton

9. Ocular tubercle glabrous, without spines ...................................... 10

Ocular tubercle slender, with 2 to 4 short spines ..............................17

10. Lateral processes without tubercles; 2 nd scape segment more slender than $1 \mathrm{st}$; long abdominal spines in single dorsal group .......................E. hispida (Krøyer) Lateral processes with 1 or 2 slender tubercles; scape segments approximately the same diameters; long abdominal spines scattered, not grouped ....................11

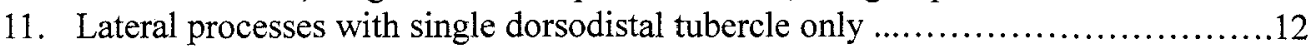

Lateral processes with 2 dorsolateral tubercles ............................... 15

12. First coxae without tubercles or spines ........................E. antarctica Child First coxae with tubercles or spines.......................................13

13. Trunk anterior with pair of slender tubercles over chelifore insertion; coxa 1 with short spines ................................................ arctica Child Trunk anterior without tubercles; coxa 1 with tall tubercles ......................14

14. Lateral processes with tall tubercle; palpi with long feathered spines

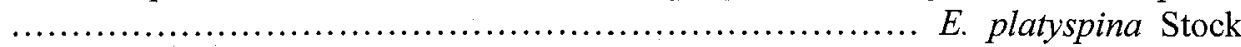
Lateral processes with low tubercle; palpi with short spines ( $q$ only). E. acanthopus Stock

15. Lateral processes and coxa 1 with clubbed spines, posterior one curved. E. curvata Child Lateral processes and coxa 1 with stout spines 
16. Ocular tubercle low; abdomen short, carried horizontally, with short spines

Ocular tubercle tall; abdomen long, erect, with long spines......E. muricata Child

17. Lateral processes with tall dorsal spiniform tubercles; ocular tubercle with several short spines; coxa 1 with dorsal and smaller posterior tubercles ...E. clitellaria Stock Lateral processes without dorsal tubercles; ocular tubercle with two or four spines .18

18. First coxae with single large dorsodistal tubercle; ocular tubercle with 2 spines ( 9 only) ................................................... unispina Stock First coxae with 2 dorsodistal tubercles; ocular tubercle with 4 spines E. spinosa Hilton

\section{Eurycyde flagella, new species}

(Figs. 1-2)

Material examined

1 male (holotype), washed from dead coral substratum, coral reef, intertidal zone, near PMBC, Phuket Island. 8 Oct. 1998. (PMBC No. 17224). 1 female (paratype), the same locality. 8 Oct. 1998. (PMBC No. 17225).

\section{Distribution}

Known only from the type locality, Phuket, intertidal zone.

\section{Description}

Holotype: Size small, leg span about $7 \mathrm{~mm}$. Trunk long oval in dorsal view, segments swollen at their posteriors. Lateral processes twice longer than their proximal diameters, separated distally by at least their diameters. First to third pairs of lateral processes armed with tall tubercles, tubercles about three times taller than basical diameters. Tubercles of fourth pair of lateral processes low. Ocular tubercle tall, slender, about four times longer than maximum diameter, armed with three long feathered spines at tip, eyes large. Proboscis typical of genus, carried on cylindrical basal segment. Abdomen longer than ocular tubercle, erect, armed with six long spines in lateral array at mid top bend.

Chelifores slender, first scape segments slightly longer than proboscis proximal stalk, with long spine dorsodistally. Second segments longer than first, downcurved, with dorsal and distal rows of several long spines of varying length. Chelae stubs with single short setae.

Palpi, first two segments short, second with dorsal tubercle distally, second longest, twice longer than first, fifth shorter than third, distal five segments armed with setae ventrally, most setae longer than segment diameters.

Ovigers, typical for this genus, fourth segments slightly longer than fifth, both armed several short lateral setae. Strigilis with two rows of denticulate spines, endal spines short, having fine serrations, ectal spines having 4-5 lateral lobes per sides, arranged in formula, right $5: 3: 3: 5$, left $5: 3: 3: 4$, endal spines having tiny denticulations, arranged in formula $6: 3: 3: 4$. Terminal claw long, as long as terminal segment.

Legs, first and second coxae, each armed with two long feathered spines, spines more than three times longer than segment diameters, each feathered with many microsetae over 
most of its length. Coxa 3 without long spines. All three major segments with long setae, setae more than five times longer of segment diameters. First tibia longer than femur, almost as long as second. Femoral cement gland with tube, no swelling, located posterior margin of femur, at half of femur length. Propodus about four times tarsus length, slightly curved. Terminal claw curved, robust, about one third of propodus length.

Paratype (female): Slightly larger than male in all lengths. Distal tubercles on lateral processes almost the same as male; those on 1st to 3rd tall, 4th low. Ocular tubercle armed with three long spines at tip. Oviger strigilis denticulate spines in formula, right $5: 3: 3: 5$, left 6:3:3:5. Long spines on coxa 1 and coxa 2 as long as those of male.

Measurements (in $\mathrm{mm}$ )

Trunk length (chelifore insertion to 4 th lateral processes), 1.03; trunk width (across 2nd lateral processes), 0.93 ; proboscis, proximal stalk length 0.28 ; distal segment length 0.75 ; abdomen length, 0.46 ; third leg length, coxa $1,0.18$; coxa $2,0.25$; coxa $3,0.13$; femur, 0.57 ; tibia $1,0.74$; tibia $2,0.74$; tarsus, 0.10 ; propodus, 0.39 ; claw, 0.17 .

\section{Etymology}

The species name is from the Latin flagella (whip), and refers to the very long spines of ocular tubercle, abdomen, chelifores, first and second coxae.

\section{Remarks}

There are 18 species of Eurycyde already reported. The new species, E. flagella, is characteristic with tall dorsodistal tubercles on the anterior three pairs of lateral processes, three long spines on the ocular tubercle, and bilateral long feathered spines on coxa 1 and coxa 2. It is distinct from other species most characteristic with the two long spines but no tubercle on coxa 1. It also differs from others in the combination of (1) number of long spines on the ocular tubercle, (2) single tall dorso-distal tubercles on anterior three pairs of lateral processes, and (3) shape and location of femoral cement gland of male.

Seven known species of Eurycyde have long spines at the tip of ocular tubercle like $E$. flagella. The new species, however, has distinct characteristics from each of known species. E. flagella resembles E. raphiaster from the Atlantic Ocean and Gulf of Mexico, in having the lateral processes armed with tall tubercles. Differences between E. flagella and $E$. raphiaster are; no long spines in the latter on coxa 1, 3 long spines on the ocular tubercle in the former but 6 in the latter, and the shape and location of the femoral cement gland in the male. Eurycyde setosa, collected at Tioman Archipelago of South China Sea, differs from the new species having 2 tubercles on coxa 1, but no long spines, having low dorso-distal tubercles on the lateral processes, and 7 long spines on the ocular tubercle. The location of femoral cement gland is at proximal part of femur in contract to that of the new species in the middle. Eurycyde longioculata collected at Bora-Bora has no tubercles on the lateral processes and no spines on coxa 1 and coxa 2 differnt from the new species. Both $E$. gorda from Caribbean and E. sertula from Guam Island have lateral processes touched or separated by narrow intervals, while those of the new species are apart. E. diacanta from Cape Verde Islands and E. longisetosa from Pacific side of Isthmus of Panama have no tubercles on the lateral processes and 2 tubercles on coxa 1 quite different from the new species. 


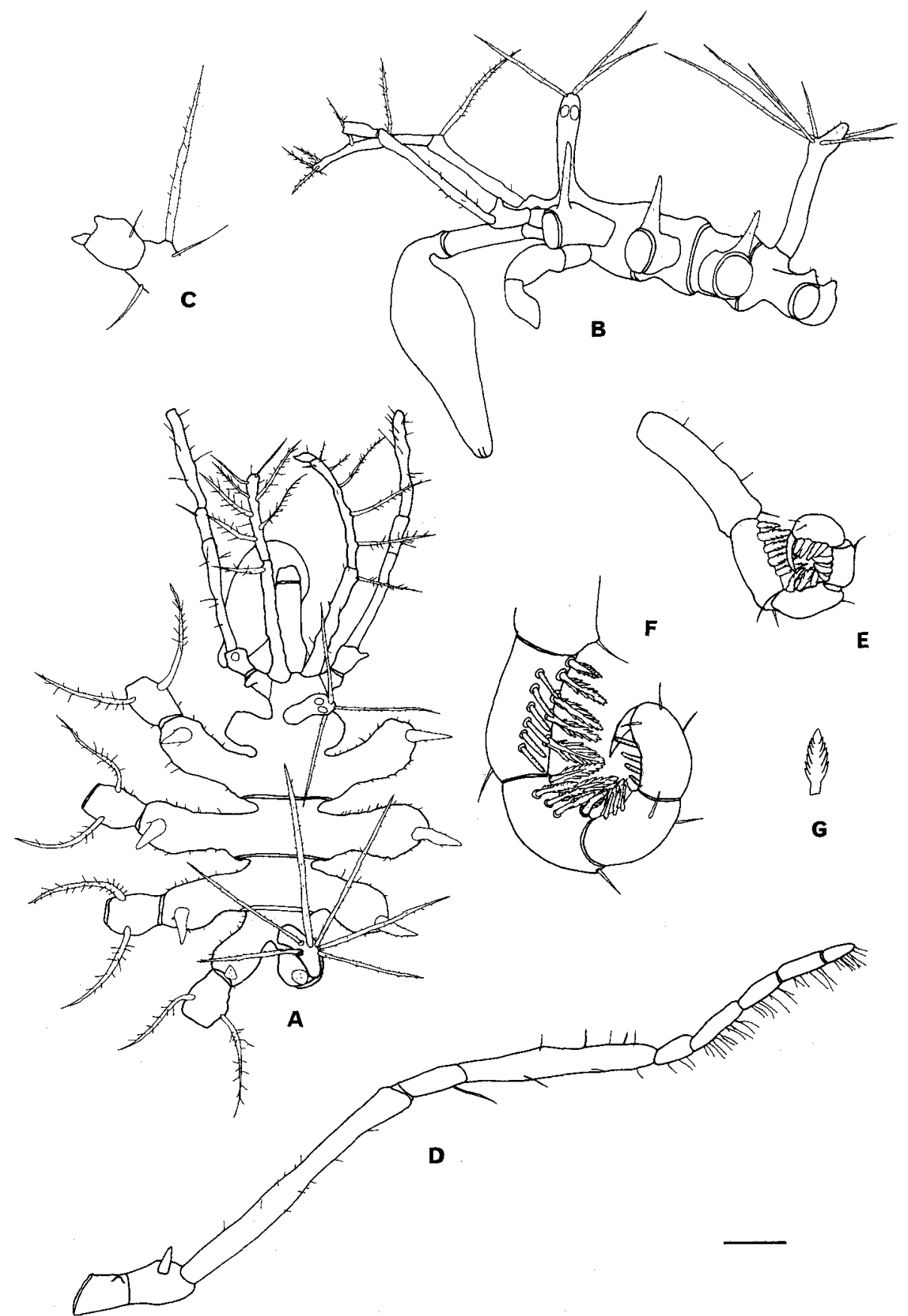

Fig.1. Eurycyde flagella, new species, male holotype: A, Trunk, dorsal view; B, Trunk, lateral view; C, Terminal segment of chelifore; D, Palp; E, Terminal segments of oviger, ectal view; F, Terminal segments of oviger, endal view; G, Denticulate spine of 7 th segment of oviger. Scale bar: $0.2 \mathrm{~mm}$ for $\mathrm{A}$ and $\mathrm{B}, 0.1 \mathrm{~mm}$ for $\mathrm{D}$ and $\mathrm{E}, 0.05 \mathrm{~mm}$ for $\mathrm{C}, \mathrm{F}$ and $\mathrm{G}$. 


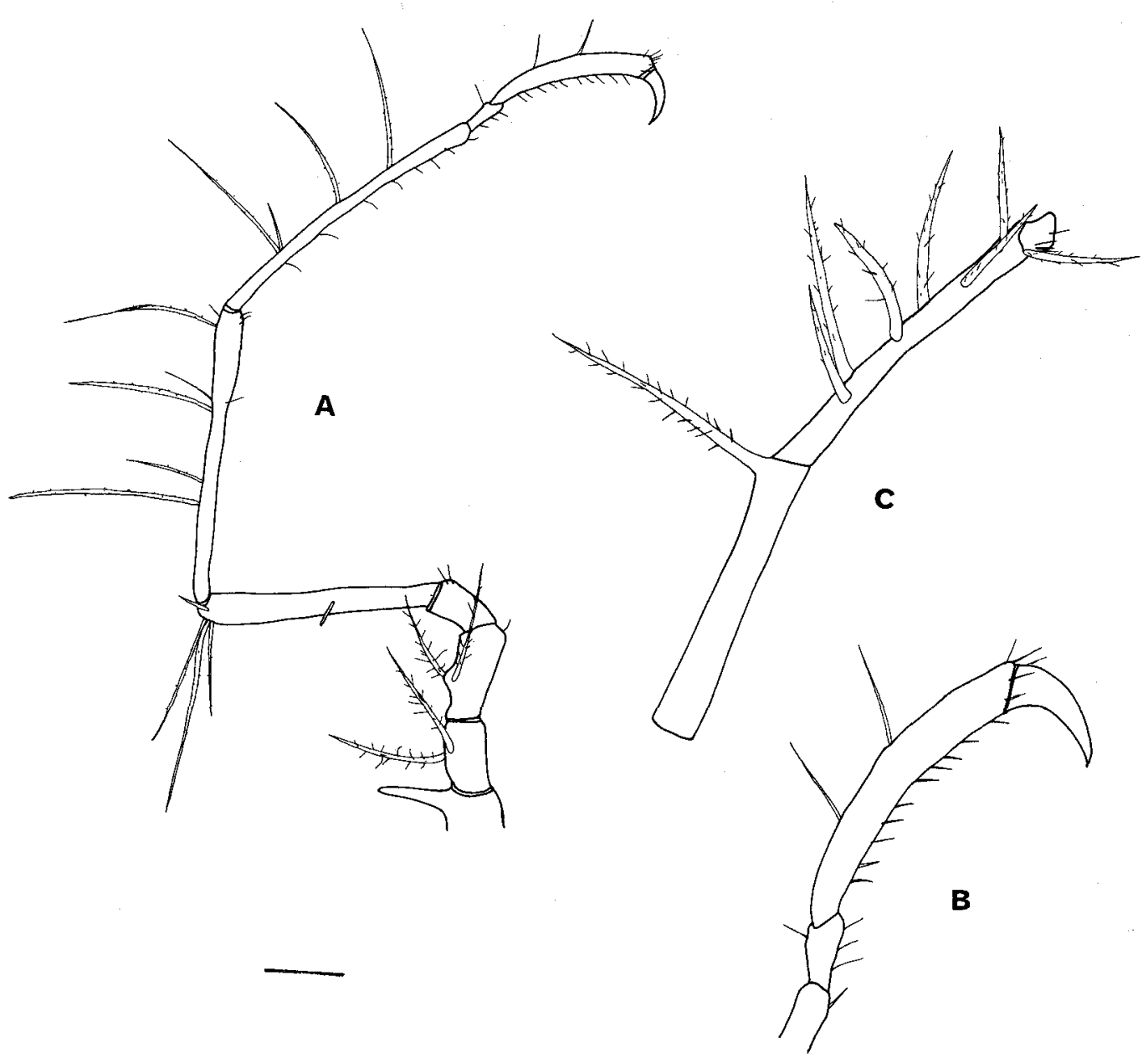

Fig.2. Eurycyde flagella, new species, male holotype: A, Third leg with distal part of lateral process; B, Terminal segments of third leg; C, Female paratype: Chelifore. Scale bar: $0.2 \mathrm{~mm}$ for $\mathrm{A}, 0.1 \mathrm{~mm}$ for $\mathrm{B}$ and $\mathrm{C}$.

\section{Acknowledgments}

We are deeply indebted to Mr. Praween Limpasaichol, the Directer of Phuket Marine Biological Center (PMBC), Mr. Somchai Bussarawit of PMBC, and all the staff of PMBC for their kind and effective cooperation in our study. This study was supported in part by Japan Society for the Promotion Science, under the Scientist Exchange Program between Japan Society for the Promotion of Science and National Research Council of Thailand. 


\section{References}

Child, C. A. 1979. Shallow-water Pycnogonida of the Isthmus of Panama and the coasts of Middle America. Smithsonian Contributions to Zoology, 293: 1-986.

Child, C. A. 1987. New and little known Pycnogonida from Antarctic and Subantarctic waters. Proceedings of the Biological Society of Washington, 100(4): 902-916.

Child, C. A. 1988. Pycnogonida of the Western Pacific Islands, III: Recent Smithsonian-Philippine Expeditions. Smithsonian Contributions to Zoology, 468: 1-32.

Child, C. A. 1991. Pycnogonida of the Western Pacific Islands, IX: A Shallow-water Guam survey, 1984. Proceedings of the Biological Society of Washington, 104(1): 138-146.

Child, C. A. 1992a. Shallow-water Pycnogonida of the Gulf of Mexico. Memoirs of the Hourglass Cruises, 9(1): $1-86$.

Child, C. A. 1992b. Pycnogonida of the Southeast Pacific Biological Oceanographic Project (SEPBOP). Smithsonian Contributions to Zoology, 526: 1-43.

Child, C. A. 1995. Pycnogonida of the Western Pacific Islands, XI: Collections from the Aleutians and Other Bering Sea Islands, Alaska. Smithsonian Contribution to Zoology, 569: 1-30.

Child, C. A. and Hedgpeth, J. H. 1971. Pycnogonida of the Galapagos Islands. Journal of Natural History, 5: 609-634.

Hilton, W. A. 1916. A remarkable pycnogonid. Journal of Entomology and Zoology of Pomona College, 8(1): 19-24; 1-6.

Hilton, W. A. 1942. Pycnogonids from the Allan Hancock Expeditions. Reports of the Allan Hancock Pacific Expedition, 5(9): 227-239; XXXV-XLVIII.

Krøyer, H. 1844. Bidrag til Kundskab om Pycnogonderne eller Søspindlerne. Naturhistorisk Tidsskrift, Kjøbenhavn, (2)1: 90-139; I.

Loman, J. C. C. 1912. Note préliminaire sur les "Podostomata" (Pycnogonides) du Musée Océanographique de Monaco. Bulletin de l'Institut Océanographique, 239: 1-14.

Müller, H. -G. 1990. Flashwasser-Pantopoden von Bora-Bora, Gesellschaftsinseln, S-Pazifik, mit zwei Neubeschreibungen. Senckenbergiana Biologica, 70: 185-201.

Müller, H. -G. 1991. Pycnogonida from Malaysian coral reefs, including descriptions of three new species. Bonner Zoologische Beiträge, 43(1): 155-178.

Sars, G. O. 1891. Pycnogonidea. Norwagian North-Expedition, 1876-1878, 6(zool.20): 1-163; I-XV, 1, 1 map.

Stock, J. H. 1955. Pycnogonida from the West Indies, Central America and the Pacific Coast of North America. Papers from Dr. Mortensen's Pacific Expedition 1914-1916. Videnskabelige Meddelelur fra Dansk Naturhistorisk Naturhistorisk Forening; Kjøbenhavn, 117: 309-366.

Stock, J. H. 1979. Pycnogonida from the Mediolittoral and Infralittoral Zones in the Tropical Western Atlantic. Studies on the Fauna Curaças and other Caribbean Islands, 59(184): 1-32.

Stock, J. H. 1986. Pycnogonida from the Caribbean and the Straits of Florida. Bulletin of Marine Science, 38(3): 399-441.

Stock, J. H. 1990. Macronesian Pycnogonida. Zoologische Mededelingen, 63(16): 205-233.

Stock, J. H. 1992. Pycnogonida from Southern Brazil. Tijdschrift voor Entomologie, 135: 113-140. 